Original Research Article

\title{
A prospective study on the pattern of antibiotic use in a tertiary care hospital
}

\author{
Susan Mani*, T. S. Hariharan
}

Department of Pharmacology, MOSC Medical College, Kolenchery, Kerala, India

Received: 05 July 2017 Accepted: 28 July 2017

\section{*Correspondence to: Dr. Susan Mani, Email: susanmani74@ yahoo.com}

Copyright: () the author(s), publisher and licensee Medip Academy. This is an openaccess article distributed under the terms of the Creative Commons Attribution NonCommercial License, which permits unrestricted noncommercial use, distribution, and reproduction in any medium, provided the original work is properly cited.

\begin{abstract}
Background: Indiscriminate use of antimicrobials is rampant throughout India, and this is a matter of serious concern. There are several reports linking antibiotic usage to bacterial resistance. Towards addressing this problem, community wise surveillance needs to be undertaken to monitor antibiotic exposure including their misuse. This study was meant to assess the extent and pattern of antibiotic use in a tertiary care facility.

Methods: Subjects for study were patients attending a suburban hospital in central Kerala. Case records of patients who were prescribed systemic antibiotics were perused for relevant data. Seriously ill patients were excluded from the study.

Results: 610 encounters with antibiotics could be identified from a total of around 2000 patient records, indicating an encounter rate of $29 \%$; which is quite acceptable as per the WHO standard of prescribing indicators. However, more than $70 \%$ of prescriptions carried only brand names of medications. Use of antibiotics was mostly on the basis of clinical symptoms (presumptive), and culture reports were not given due credence. Prescriptions were invariably therapeutic in nature, and the concepts of surgical prophylaxis conveniently given a go by. The most common infections were those of the Upper Respiratory Tract (URTI), followed by skin and soft tissue infections. Ampicillin, azithromycin and cefuroxime were the most frequently prescribed agents. More than one third of infections were treated with a combination of antimicrobials. A general temptation for using cephalosporin - betalactamase inhibitor combinations could be related to the aggressive promotional policies of the pharmaceutical industry. Conclusions: The overall antibiotic encounter rate is acceptable as per WHO standards. But the tendency for using injections as well as antibiotic combinations is very high. Prophylactic use of antibiotics in surgical procedures is not being followed at all. A serious attempt needs to be made to implement National Guidelines for use of antimicrobials.
\end{abstract}

Keywords: Antimicrobials, Empirical, Generic prescriptions, Prescribing indicators, Prophylactic use

\section{INTRODUCTION}

Antibiotics, as a category, constitute one of the most frequently misused medicines in India, with sales exceeding Rs. 1000 crores per annum. Indiscriminate and unscientific prescriptions along with self medication of by patients, have contributed to the development of bacterial resistance to these agents. Use of anti-infective agents in farm animals and poultries has also played a significant role in this regard. No wonder, innumerable lives have been lost due to infections with superbugs that have developed resistance to a great majority of antibiotics.

Proper antibiotic selection requires knowledge of the susceptibility of the causative pathogen as well as the pattern of antibiotic use, both of which are known to differ from region to region and between different hospitals in the same region.

Data are lacking on antibiotic use at the level of primary health care, especially in low and middle income countries. 
The World Health Assembly meeting of May 2015, at Geneva had directed member countries to frame concrete plans for optimizing use of antibiotics, through necessary protocols and guidelines, and has set May 2017 as the deadline. ${ }^{1}$ Many organizations have also called for strategies involving surveillance systems to assess antibiotic use in the community. ${ }^{2}$ It is on these lines that the current study was undertaken with a view to monitor the prescribing habits of the doctors working in this institution.

Established in 1970 as a 100 bedded facility, this mission hospital evolved into a full-fledged teaching institution by 2002. Necessary systems are steadily being put in place since then. A broad policy on the use of antibiotics has also been framed, but, the follow up measures have not been satisfactory. This scenario also contributed to the conduct of this survey. The present attempt, it is hoped would provide the much needed database for optimizing the use of antibiotics.

\section{METHODS}

\section{Population and health care setting}

A prospective study was undertaken in patients attending a tertiary health care facility, located in Kolenchery, a suburban township in Ernakulum district of Kerala state. A 1200 bedded teaching hospital with an average admission of 25,000/year, the institution has a full-fledged department of microbiology with necessary facilities for culture and susceptibility testing and authentic reporting. Around 60 antibiotics of differing strengths and formulations, including FDCs are being stocked regularly in the hospital pharmacy.

\section{Study design}

The study involved perusal of records and charts of patients over a period of 8 months from October 2014 to May 2015. The sample size for the study was chosen as per WHO guidelines on 'How to investigate drug use in health facilities. ${ }^{3}$ Accordingly, 610 records of patients with antibiotic encounters were finalized from a total of 2100 patient records.

\section{Inclusion criteria}

- Both inpatients and outpatients from clinical departments including specialty departments.

- $\quad$ Patients of all age groups and genders.

- All patients receiving at least one antibiotic for therapeutic or prophylactic purpose.

\section{Exclusion criteria}

- $\quad$ Patients of Intensive Care Unit (ICU).

- Those receiving topical antibiotics only.

- Patients on cancer chemotherapy, immunosuppression and dialysis.
- Those with specific infectious diseases including tuberculosis, malaria, Leprosy, fungal and viral infections.

Demographic particulars of patients, details of antibiotics prescribed and related aspects of their use were collected on a day to day basis for outpatients. In the case of inpatients data collection was done on the day after their discharge from the hospital. Computerized data from the hospital pharmacy pertaining to total quantity of antibiotics dispensed every week were also obtained for comparison. Culture and sensitivity reports on all biological samples sent from hospital wards were also recorded. Data collected were entered in a prescribed format, and subjected to interpretation and analysis. The WHO prescribing indicators for this study were calculated and are presented under the results. ${ }^{4}$

\section{RESULTS}

\section{Demographic characteristics of patients}

Of the 610 patient encounters with antibiotics, 325 were males and 281 females; 84 patients were of the paediatric age group (1 month - 12 years), and 44 were newborns.

\section{Types of infection treated}

The most common infections were those involving upper respiratory tract and skin and soft tissue. Infections related to trauma also accounted for a significant number of cases (Figure 1).

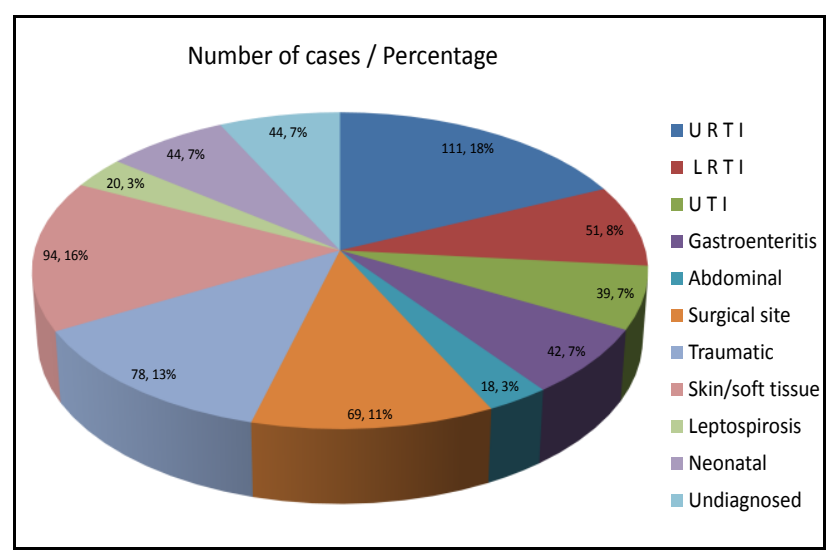

Figure 1: Incidence of infections.

A notable feature is that 20 patients presenting with high fever and jaundice were diagnosed to have Leptospirosis. However, there was total absence of cases of syphilis or acute rheumatic during the study period.

\section{Antibiotics used}

A total of 40 different antimicrobials, either alone or in different combinations (polytherapy) had been prescribed. These included: 
Betalactams including BLI combinations (20), Macrolides (4), Flouroquinolones (4), Tetracyclines (3), Aminoglycosides (2), Imidazoles (2) and Odd antimicrobials (5).

Table 1: Encounter rates for antimicrobials.

\begin{tabular}{|llll|}
\hline Antibiotics & $\begin{array}{l}\text { Number of encounters } \\
\text { Single } \\
\text { agents }\end{array}$ & Combinations & $\begin{array}{l}\text { Total (\%) } \\
\text { n=610 }\end{array}$ \\
\hline Penicillins & 59 & 60 & $119(20)$ \\
\hline Macrolides & 98 & --- & $98(16)$ \\
\hline $\begin{array}{l}\text { Beta lactam -BLI } \\
\text { +/- others) }\end{array}$ & 59 & 31 & $90(15)$ \\
\hline Cephalosporins & 80 & ---- & $80(13)$ \\
\hline Imidazoles & ---- & 78 & $78(13)$ \\
\hline Aminoglycosides & --- & 48 & $48(08)$ \\
\hline $\begin{array}{l}\text { Flouroquinolone } \\
\text { s }\end{array}$ & 45 & ---- & $45(07)$ \\
\hline Cotrimoxazole & 26 & --- & $26(04)$ \\
\hline Tetracyclines & 08 & ---- & $08(01)$ \\
\hline Others & 18 & --- & $18(03)$ \\
\hline Total & 393 & $217(36 \%)$ & 610 \\
\hline
\end{tabular}

Among individual agents, ampicillin, azithromycin and cefuroxime were the most preferred ones for aerobic bacterial infections, whereas anaerobic infections were mostly managed by metronidazole. Ampicillin was prescribed both as a single agent, as well as a fixed dose combination with cloxacillin. The data for commonly prescribed antibiotics are shown in Table 1.

\section{Monotherapy vs polytherapy}

Altogether, 393 patients $(64 \%)$ were treated with single agents and 217 (36\%) received combinations with two or more agents (FDCs prescribed were 84). (Table 2, Figure 2).

Infections of upper respiratory tract (URTI) and Leptospirosis and most of the urinary tract infections
(UTI) were mostly managed with a single antimicrobial agent. Most of the patients with URTI received macrolides or cotrimoxazole. Extended spectrum penicillins and cephalosporins were the choice agents in Leptospirosis, whereas, flouroquinolones topped the list in management of UTI (Table 3, Figure 3).

Table 2: Individual infections treated with mono/polytherapy.

\begin{tabular}{|lll|}
\hline Diagnosis & $\begin{array}{l}\text { Monotherapy } \\
(\%)\end{array}$ & Polytherapy \\
\hline URTI (111) & $111(100 \%)$ & nil \\
\hline Leptospirosis (20) & $20(100 \%)$ & nil \\
\hline UTI (39) & $30(77 \%)$ & 09 \\
\hline $\begin{array}{l}\text { Abdominal infections } \\
(18)\end{array}$ & $06(33 \%)$ & 12 \\
\hline Gastroenteritis (42) & $28(67 \%)$ & 14 \\
\hline Skin / soft tissue (94) & $52(55 \%)$ & 42 \\
\hline Trauma wounds (78) & $36(46 \%)$ & 42 \\
\hline Surgical wounds (69) & $40(58 \%)$ & 29 \\
\hline Neonatal infections (44) & $12(27 \%)$ & 32 \\
\hline LRTI (51) & $28(55 \%)$ & 23 \\
\hline $\begin{array}{l}\text { Uncertain diagnosis } \\
(44)\end{array}$ & $30(68 \%)$ & 14 \\
\hline Total & $393(64 \%)$ & 217 \\
\hline
\end{tabular}

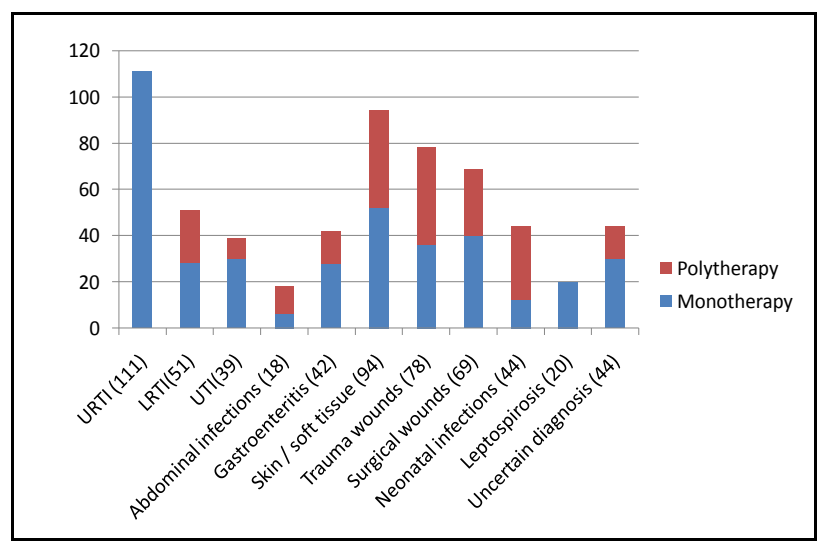

Figure 2: Monotherapy vs polytherapy.

Table 3: Particulars of monotherapy in individual infections.

\begin{tabular}{|lllllllll|}
\hline INFECTIONS & PNCLN & CFLSP & BL-BLI & MCLD & FQLN & TCYCL & CTMX & Others \\
\hline URTI (111) & 0 & 0 & 12 & 66 & 10 & 0 & 21 & 02 \\
\hline LRTI (28) & 05 & 04 & 08 & 11 & 0 & 0 & 0 & 0 \\
\hline UTI (30) & 0 & 05 & 0 & 0 & 18 & 0 & 05 & 02 \\
\hline Abdominal infections (06) & 0 & 0 & 06 & 0 & 0 & 0 & 0 & 0 \\
\hline Gastroenteritis (28) & 0 & 23 & 0 & 0 & 05 & 0 & 0 & 0 \\
\hline Skin / soft tissue (52) & 13 & 10 & 06 & 11 & 04 & 08 & 0 & 0 \\
\hline Trauma wounds (36) & 0 & 12 & 20 & 04 & 0 & 0 & 0 & 0 \\
\hline Surgical wounds (40) & 21 & 14 & 05 & 0 & 0 & 0 & 0 & 0 \\
\hline Neonatal infections (12) & 0 & 0 & 0 & 0 & 0 & 0 & 0 & 12 \\
\hline Leptospirosis (20) & 12 & 08 & 0 & 0 & 0 & 0 & 0 & 0 \\
\hline Uncertain diagnosis (30) & 08 & 04 & 02 & 06 & 08 & 0 & 0 & 02 \\
\hline Total & 59 & 80 & 59 & 98 & 45 & 08 & 26 & 18 \\
\hline
\end{tabular}




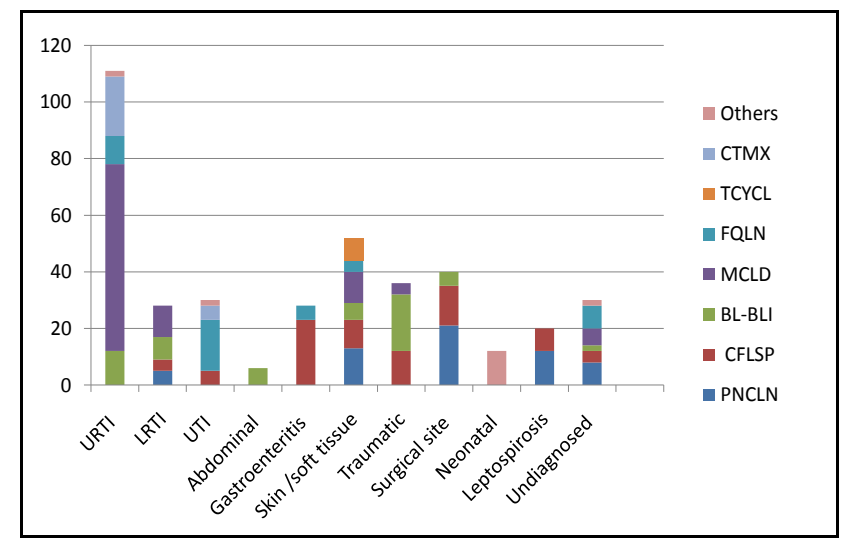

Figure 3: Monotherapy in infections.

A full course of therapy involving a combination of antimicrobials (polytherapy) was instituted in a significant proportion of patients $(36 \%)$, especially so in the case of neonatal and abdominal infections. The most preferred combinations were those involving nitroimidazoles and betalactams with aminoglycosides (Table 4, Figure 4).

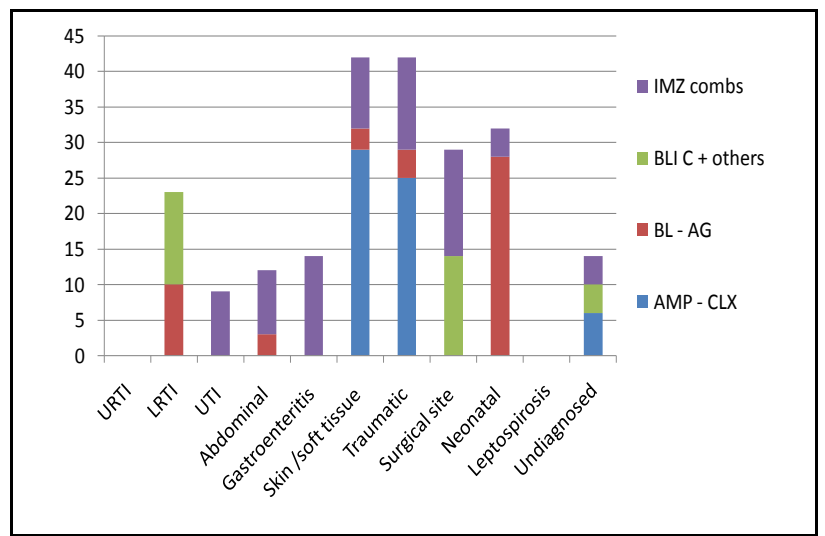

Figure 4: Polytherapy in infections.

Table 4: Particulars of antimicrobial combinations in individual infections.

\begin{tabular}{|lllll|}
\hline Infections & $\begin{array}{l}\text { Ampicillin- } \\
\text { Cloxacillin }\end{array}$ & $\begin{array}{l}\text { Beta lactams - } \\
\text { Amino }\end{array}$ & $\begin{array}{l}\text { BLI combns with other } \\
\text { agents }\end{array}$ & $\begin{array}{l}\text { Imidazole } \\
\text { combns }\end{array}$ \\
\hline URTI (0) & 0 & 0 & 0 & 0 \\
\hline LRTI (23) & 0 & 10 & 13 & 0 \\
\hline UTI (09) & 0 & 0 & 0 & 09 \\
\hline Abdominal infections (12) & 0 & 03 & 0 & 09 \\
\hline Gastroenteritis (14) & 0 & 0 & 0 & 14 \\
\hline Skin / soft tissue (42) & 29 & 03 & 0 & 10 \\
\hline Trauma wounds (42) & 25 & 04 & 0 & 13 \\
\hline Surgical wounds (29) & 0 & 0 & 14 & 15 \\
\hline Neonatal infections (32) & 0 & 28 & 0 & 0 \\
\hline Leptospirosis (0) & 0 & 0 & 0 & 04 \\
\hline Uncertain diagnosis (14) & 06 & 0 & 04 & 78 \\
\hline Total & 60 & 48 & 31 & 04 \\
\hline
\end{tabular}

\section{Pattern of antibiotic use}

Drug management of infections was invariably empirical, based on the best guess. Even in the few instances (22\%), where biological samples were sent for culture and sensitivity, the reports had very little impact on antibiotic selection. Change over to fresh antibiotics as per sensitivity report was effected only in a handful of patients.

The values for WHO Prescribing indicators regarding antibiotic use are specified below; the ideal figures are also indicated alongside. ${ }^{4}$

1. Percentage of encounter with antibiotics $\rightarrow 29 \%$; (610//2100) (desired 20 - 26\%)

2. Percentage of anti bacterials from WHO EDL $\rightarrow$ 69\%; (22/32) (desired 100\%)
3. Percentage of encounter with injection $\rightarrow 48 \%$; (295/610) (desired $13.4-24.1 \%$ )

4. Percentage of drugs prescribed in generics $\rightarrow 31 \%$; $(188 / 610)=($ desired $100 \%)$

\section{DISCUSSION}

Even though it was established more than 40 years back, the hospital has transformed into a teaching facility only during the last 12 years. A comprehensive set of guidelines for use of antibiotics has since been evolved, but compliance with these is still lacking. Consequently, there exists a great diversity in the number of antibiotics and their combinations being used. The regimens employed also differ among various specialties and super specialties. The WHO prescribing indicators provided earlier, gives a comprehensive idea regarding the pattern of antibiotic use in this institution. 
The overall antibiotic encounter rate as per our study was $29 \%$, which is not much different from the WHO standard of $20-26.8 \%$. This is certainly a welcome attitude, and could reflect the concern of the practicing doctors for the rapidly spreading bacterial resistance. This is significantly less than the values reported from many other parts of India - $(47.6 \%, 73.1 \%, 76.5 \%$ and $81.8 \%$ from T.puram, Chennai, Vellore and Lucknow) respectively. ${ }^{5}$ The IJMR study was confined to common acute infections in primary and secondary health care facilities, whereas our study covered a tertiary care facility with a significant number of referred patients attending superspeciality disciplines.

As per our study, the percentage of antibacterials agents figuring in the Essential Drug List of WHO was 69\% (ideal $100 \%) .{ }^{6}$ Whereas, a similar study in South Kerala revealed a figure of $81 \% .{ }^{7}$ A glance at the WHO list shows that the following agents were being completely avoided in our hospital - penicillin $\mathrm{G}$ (all 3 forms), penicillin $\mathrm{V}$, ceftazidime, chloramphenicol, trimethoprim, kanamycin and a few others. Rheumatic fever and syphilis cases are being reported very rarely in this region, and the possible risk of fatal anaphylaxis could explain the avoidance of Penicillin G injections. Pencillin V, mostly used for pharyngitis in children, requires a $6^{\text {th }}$ hourly scheduling and its poor compliance probably acts as deterrent for its prescription, especially with the availability of equally effective amoxicillin. The main drawback for ceftazidime is its reduced activity for Gram negative rods (except $P$. aeuroginosa), when compared to the other third generation cephalosporins (This is only a complimentary drug in the WHO model list). The lack of use of Imipenem - cilastatin and Kanamycin can be explained by the availability of meropenem and amikacin as effective substitutes.

Encounters with injectable antibiotics were $48 \%$ in our study (Ideal $13.4-24.1 \%$ ), whereas it was $60 \%$ in an earlier study from Kerala and $96 \%$ in the central Indian study., In another study from South India, the percentage of injections was as low as $1.6 \% .^{9}$ It is a well-accepted fact that parenteral therapy is significantly costlier, because of the higher price for the formulations, the cost of the syringes as well as nursing charges. The significant reduction in the use of injectables in this institution deserves appreciation.

However, many hospitalized patients had been treated initially with injections involving ampicillin, to be switched over to oral ampicillin to complete the course. This is surprising since bioavailability of oral ampicillin is highly inadequate and variable. The proper course would have been to continue treatment with amoxicillin capsules

Overall, only $31 \%$ of prescriptions were using generic names of antibiotics. This is very low when compared to the WHO standard (ideal 100\%). Generic prescription dominated in the neonatology department (80\%), whereas, in general surgery, use of brand names was the routine (generic prescription only 14\%). In other departments, generic prescriptions equaled branded ones.
The practice of using generic names in prescriptions is yet to catch up throughout India. Surveys from different parts of the country reveal highly divergent figures- Nagpur (Central India) 49\%, South India 43\%, Bhopal (3.6\%). ${ }^{8-10}$ On the other hand, an Ethiopian study shows that $99 \%$ prescriptions were in generic names. ${ }^{11}$ No wonder the Medical Council of India, the regulatory authority for practice of modern medicine, has recently come out with a stipulation that every physician should prescribe drugs with generic names legibly and preferably in capital letters. $^{12}$

The selection of individual agents in most instances raises a big question mark on their scientific basis. Lab reports from microbiology had not been given due relevance and no attempt made to switch over to definitive line of management in majority of infections. This also appears to be the situation in many developing countries. ${ }^{13,14}$ The disinclination towards relying on culture and sensitivity could be due to many factors, like rich clinical experience of doctors, lack of rapid detection methods for pathogens and the extra cost factor.

As for use of individual agents, ampicillin, azithromycin and cefuroxime were the most preferred ones, with metronidazole for anaerobic infections. This compares well with the study results from Andhra Pradesh, where ampicillin, cefexime, and metronidazole occupied the top positions. ${ }^{13}$ On the other hand, in the Karnataka survey, flouroquinolones along with cefalosporins constituted the most frequently used agents. ${ }^{15}$ Region wise variations in microbial susceptibility might be responsible for the disparity in the choice of suitable agents.

Among doctors there were few takers for older inexpensive agents like tetrayclines, maybe due to lack of bactericidal effect and the fear of possible resistance. The use of tetracyclines, however, was high in the rural hospital setup in the Vellore study. ${ }^{16}$ Among the newer agents, meropenem, linezolid and tigecycline found only very little usefulness probably due to their high cost and because of exclusion of ICU patients from this study.

One matter of serious concern is the increasing tendency for use of antibiotic combinations (36\%), which is significantly higher when compared to reports from developed countries like UK and US (18\% and $20 \%$ respectively). ${ }^{17,18}$ However, this was much lower than $71 \%$ and $45 \%$ reported from North India study and Malaysia respectively. ${ }^{19,20}$ The use of an aminopenicillin with cloxacillin could well be justified for skin and soft tissue infections (both streptococci and S. aureus implicated), but the widespread use of combinations involving third generation cefalosporins with BLIs in the general surgery and neurosurgery departments is baffling. While BLI combinations with extended spectrum penicillins have a scientific basis and are approved for use in US and UK, the benefits of combining BLIs with cefalosporins have not been clearly established. In this regard, our own study did reveal that all BLIs need not enhance cephalosporin 
activity - while Tazobactam and sulbactam had a positive effect, no benefits accrued by combining clavulanate with third generation cefalosporins. ${ }^{21}$ One important factor that seems to have influenced antibiotic use in our hospital was the ready availability of all the desired combinations in the hospital pharmacy.

The commonest infections clinically diagnosed were those of the upper respiratory tract $(18 \%)$, and skin and soft tissue (16\%). In a study done in Maharashtra, the incidence of URTI were found to be only $8.2 \%$, whereas in another study in Tamil Nadu, the prevalence of URI was found to be $27 \% .^{22,23}$

\section{Antibiotic selection in infections}

Management of infections like URTI, Leptospirosis as well as UTI with a single antimicrobial could be appreciated, though this was probably feasible as the involved pathogen could be correctly guessed/ identified.

For URTI, especially pharyngitis choice of azithromycin could be due to a better compliance and shorter course of therapy vis a vis an oral penicillin. ${ }^{24}$ Amoxicillin remains an effective substitute, and is preferred in certain regions like vellore. ${ }^{16}$ Interestingly, in the paediatric population, cotrimoxazole was favoured for URTI in this institution, as against cefixime in the study from Central India. ${ }^{8}$ These differences possibly reflect the varying resistance pattern in different communities (urban and village level) and in different regions of the country.

In outpatient management of UTI, especially as an empirical therapy, use of flouroquinolones $(60 \%)$ goes certainly against the currently accepted policy. Nitrofurantoin is now considered as the first line agent for treatment and prophylaxis of lower UTI, based on its proved effectiveness and established safety accrued from its long term use. ${ }^{24,25}$ In fact, the FDA 2016 guidelines insist that FQ use should be reserved for treatment of more serious and resistant infections to minimize resistance development.

A majority $(>70 \%)$ of cases of newborn infections were managed with antimicrobial combinations, ampicillin + gentamicin being the preferred one. This practice could be justified, and it conforms to the national management guidelines recommended by the Govt of India. ${ }^{26}$ Involvement of both gram positive cocci and gram negative rods is very common in neonatal sepsis and meningitis. However, a third generation cephalosporin could be a better option than gentamicin which has got poor penetration into the CSF. ${ }^{27}$

The present survey points out to the routine use of antimicrobial combinations in most cases of surgical site wounds and abdominal infections also - a cephalosporin (third generation), an aminoglycoside or a flouroquinolone has been used along with a nitroimidazole. The tendency for use of combinations indicates the blind and empirical nature of treatment and an attempt at covering all possible pathogens.

Prophylactic use of antibiotics for surgical procedures is currently the accepted policy worldwide. Treatment guidelines advocated in India also reflect this view. ${ }^{26}$ In our study, this principle is not seen to be followed - in all instances a full course antimicrobial therapy was instituted, as for the treatment of an established infection. One or two doses of an antibiotic (i.v or i.m), initiated at the time of premedication or soon after induction of anaesthesia, and repeated after $12 \mathrm{hrs}$, is all that is needed.

\section{Gastroenteritis}

Cephalosporins first and second generation was the treatment option for two thirds of patients $(67 \%)$, whereas, the rest were given combinations involving one of the nitroimidazoles. The use of antibiotics here cannot be justified as most cases are either of viral orgin or due to toxigenic $E$. coli both of which are self limiting. ${ }^{8}$

Ampicillin - cloxacillin combinations have been widely prescribed for the treatment of skin and soft tissue infections as well as trauma wounds. Judged from the presence of Strep pyogenes and Staph.aureus in severe infections like abscesses, cellulitis, furuncles and impetigo, use of this penicillin combination has a sound basis. However, the general preference for an FDC involving the two agents is distressing because of unpredictable absorption and poor patient compliance associated with both the components.

\section{CONCLUSION}

It is evident from this study, that the prescribing practices for antibiotics deviate significantly from the standards recommended by WHO. It is true that the percentage of antibiotic encounter is only $29 \%$, just a little higher than the WHO figure, but other indicators like an over reliance on parenteral administration as well as an attitude of reluctance towards switching over to generic prescriptions point to a dismal picture. Added to this is the complete avoidance of certain low cost and established antibiotics in the WHO essential drug list. Prophylactic use of antibiotics in surgical procedures is also not being followed at all. An increasing tendency for polypharmacy and for use of unscientific combinations such as Cs-BLI fixed dose combinations is also evident. The existing scenario needs concerted measures of intervention, like strict implementation of antibiotic policy and antibiotic treatment guidelines. PCR based methods for rapid and highly specific detection of pathogens would go a long way in curtailing empirical use of antibiotics and promote rationale management of infections. The department of microbiology could also become proactive by circulating periodic reports of susceptibility data for common pathogens.

\section{Funding: No funding sources}


Conflict of interest: None declared

Ethical approval: The study was approved by the Institutional Ethics Committee (No.40/2014)

\section{REFERENCES}

1. Global Action Plan on Antimicrobial Resistance, 68 World Health Assembly; May 2015, (document WHA68/2015/REC/1, Annex 3), WHO, Geneva.

2. Cars O, Högberg LD, Murray M, Nordberg O, Sivaraman S, Lundborg CS, et al. Meeting the challenge of antibiotic resistance. BMJ: British Medical Journal (Online). 2008 Sep 18;337.

3. WHO: How to investigate drug use in health facilities: selected drug use indicators; Geneva: 1993.

4. Isah AO, Ross-Degnan D, Quick J, Laing $\mathrm{R}$, Mabadeje. AFB The Development of Standard Values for the WHO Drug Use Prescribing Indicators. ICIUM/EDM/WHO. Available at: http://archives.who.int/prduc2004/rducd/ICIUM_Post ers/1a2_txt.htm.

5. Indira KK, Chandy SJ, Jeyaseelan L, Kumar R, Suresh S. Antimicrobial prescription patterns for common acute infections in some rural and urban health facilities of India. Indian Journal of Medical Research. 2008 Aug 1;128(2): 165.

6. $19^{\text {th }}$ WHO Model list of Essential Medicines; April 2015:6-9. Available at: who.int/medicines/publications/essentialmedicines/E ML2015_8-May-15.pdf.

7. Remesh A, Salim S, Gayathri AM, Nair U, Retnavally KG. Antibiotics prescribing pattern in the in-patient departments of a tertiary care hospital. Archives of pharmacy practice. 2013 Apr 1;4(2):71.

8. Narayanan DS, Mangesh MM. A study of prescription pattern of antibiotics in paediatric inpatients at a tertiary care hospital in Central India. International $\mathbf{J}$. of Pharmacological Research 2016;6(08):286-90.

9. Prasad PS, Rudra JT, Vasanthi P, Sushitha U, Sadiq MJ, Narayana G. Assessment of drug use pattern using World Health Organization core drug use indicators at Secondary Care Referral Hospital of South India. CHRISMED Journal of Health and Research. 2015 Jul 1;2(3):223.

10. Mishra S, Sharma P. Prescription audit and drug utilization pattern in a tertiary care teaching hospital in BHOPAL. International Journal of Basic \& Clinical Pharmacology. 2016;5(5):1845-9.

11. Desalegn AA. Assessment of drug use pattern using WHO prescribing indicators at Hawassa University teaching and referral hospital, south Ethiopia: a crosssectional study. BMC health services research. 2013 May 7;13(1):170.

12. Indian Medical Council (Professional conduct, Etiquette and Ethics) Regulations, 2002. Substitution in use of Generic names of drugs. Notification No. MCI-211(2)/2016(ethics)/131118; September 2016.

13. Khade AM, Shakeel M, Bashir M. Prescription pattern of antimicrobial agents in a teaching hospital of South
India. Int J Basic Clin Pharmacol. 2013 Oct;2(5):56770.

14. Giri BR, Pant HP, Ravishankar P. Surgical site infection and antibiotic use pattern in a tertiary care hospital in Nepal. J. Pak Med Assoc: 2008;58(3):14851.

15. Malpani AK, John NN, Srividya VL, Santoshi Y, Paul S. A broad survey and comprehensive study on utilization pattern of antibiotics in tertiary care teaching hospital in North Karnataka. Int J Pharm Sci Res. 2013;4(2);628-32.

16. Chandy SJ, Thomas K, Mathai E, Antonisamy B, Holloway KA, Lundborg CS. Patterns of antibiotic use in the community. $\mathrm{J}$ Antimicrob chemother. 2013;68:229-36.

17. Moss F, McNicol MW, McSwiggan DA, Miller DL. Survey of antibiotic prescribing in a district general hospital. I. Pattern of use. Lancet. 1981 Aug 15;2(8242):349-52.

18. Scheckler WE, Bennett JV. Antibiotic usage in seven community hospitals. Jama. 1970 Jul;213(2):264-7.

19. Prajapati V, Bhatt JD. Study of Prescribing Patterns of Antimicrobial Agents in the Paediatric Wards at Tertiary Teaching Care Hospital, Gujarat. Int J Pharm Sci Res. 2012;3(7):2348-55.

20. Lim VK, Cheong YM, Suleiman AB. Pattern of antibiotic usage in hospitals in Malaysia. Singapore medical journal. 1993 Dec;34:525.

21. Susan Mani, Hariharan TS. A comparative invitro study of cephalosporin - beta lactamase inhibitor combinations against gram negative bacilli: Indian $\mathbf{J}$ Physiol Pharmacol. 2013;57(4):425-31.

22. Masavkar SP, Naikwadir AM. Study of incidence of upper respiratory tract infections in urban and rural population; Sch J App Med Sci. 2016;4(6C):2023-6.

23. Sharma D, Kuppusamy K, Bhoorasamy A. Prevalence of acute respiratory infections (ARI) and their determinants in under five children in urban and rural areas of Kancheepuram district, South India. Ann Trop Med Public Health. 2013;6:513-8.

24. National symposium on antibiotic stewardship and infection control and prevention, Antibiotic Guidelines, Dep of health and FW, Govt of Kerala 2016:97,93.

25. Cunha BA, Schoch PE, Hage JR. Nitrofurantoin: preferred empiric therapy for community-acquired lower urinary tract infections. In Mayo Clinic Proceedings. 2011 Dec;86(12):1243-4.

26. National Treatment Guidelines for Antimicrobial Use in Infectious Diseases, National centre for disease control, Directorate general of Health Services, Ministry of Health \& Family Welfare, Government of India; Version 1.0. 2016:39-40.

27. Therapeutic guidelines: antibiotic version 13, by antibiotic expert group, Melbourne; 2006:55.

Cite this article as: Mani S, Hariharan TS. A prospective study on the pattern of antibiotic use in a tertiary care hospital. Int J Basic Clin Pharmacol 2017;6:2237-43. 